\title{
Quality and sensory profile evaluation of gluten-free sapodilla-wild almond seed bar with stevia as partial sugar substitution
}

\author{
*Akesowan, A., Choonhahirun, A. and Jariyawaranugoon, U. \\ Department of Food Science and Technology, School of Science and Technology, University of the Thai \\ Chamber of Commerce, 126/1 Vibhavadee-Rangsit Road., Dindaeng, Bangkok 10400, Thailand
}

\begin{abstract}
Article history:
Received: 26 December 2019

Received in revised form: 26

February 2020

Accepted: 28 February 2020

Available Online: 27 March 2020
\end{abstract}

\section{Keywords:}

Fruit bar,

Gluten-free food,

Preference mapping,

Sapodilla fruit,

Stevia,

Wild almond seed

\section{DOI:}

https://doi.org/10.26656/fr.2017.4(4).421

\begin{abstract}
This research aimed to investigate the quality of fruit bars prepared with different ratios of sapodilla-wild almond seed (80:20 and 70:30 w/w) and sugar substitution with stevia (0, $1 / 3$, and $2 / 3$ as equivalent sweetness basis). Physical properties (moisture and water activity), sensory acceptability, and preference mapping of the fruit bars were investigated. The samples formulated with a higher proportion of sapodilla pulp had higher moisture and water activity than those with less sapodilla pulp. Increasing the sugar substitution with stevia tended to decrease the moisture and water activity of the fruit bars. The stevia incorporation had effects on sensorial attributes, especially the flavor depending on how much sapodilla pulp proportion used in fruit bar preparation. The fruit bars formulated with 80:20 of the sapodilla-wild almond seed and 2/3 sugar substitution and that with $70: 30$ and full-sugar perceived the highest overall acceptability. The preference mapping revealed the importance of product attributes, and the texture was an important attribute on sensorial acceptance. In conclusion, the fruit bar prepared with $80 / 20$ of sapodilla-wild almond seed and $2 / 3$ sugar substitution with stevia was the most preferred formulation.
\end{abstract}

\section{Introduction}

The development of novel food products by using less processed local agriculture could create value-added product opportunities, provide food product diversification, reduce the loss and deterioration of agricultural produces, and promote farmer's price assurance and rural-urban linkages. In Southeast Asia, sapodilla fruit (Manilkara zapota L.) is regularly consumed fresh when ripening because of soft texture, sweet style, and attractive orange color. Sapodilla is a high-calorie fruit which is rich in calcium, iron, magnesium, vitamin A and $\mathrm{C}$, and dietary fiber (5-6 $\mathrm{g} / 100 \mathrm{~g})$. It's additionally a good source of antioxidants (polyphenol compounds and proanthocyanidins) (Lim et al., 2018; Rudrappa, 2019). Likewise, wild almond seed (Irvingia malayana) from the tropical evergreen tree species in the family Irvingiaceae contains $67 \%$ fat, 9.1\% carbohydrate, $3.4 \%$ protein, and high dietary fiber. It mainly consists of lauric (46.7\%) and myristic (40.3\%) acids and other fatty acids such as palmitic, stearic, oleic, and behenic acids (Sonwai and Pornprachanuvat, 2012). As far as the authors know, the seed is edible after roasting and tastes like chestnuts. To date, there is little information about food products processed by this local agriculture. Thus, the combination of sapodilla fruit and wild almond seed within the manufacture of healthy or functional food products is of interest to develop the value-added product that is novel and healthful.

In the last decades, most consumers are increasingly interested in food products with less sugar and fat to lower the risk of cardiovascular disease, high blood pressure, obesity, diabetes, dental decay, and some cancers (Sinchaipanit et al., 2013). In the food industry, the combined sugar substitutes are typically used in the manufacture of low-sugar foods. Stevia, a natural substance extracted from the plant leaves (Stevia rebaudiana), is a zero-calorie sweetener that is 30 to 150 times sweeter than sucrose. It has heat and $\mathrm{pH}$ stability, no tooth decay, and no effect on blood glucose and insulin levels (Gao et al., 2016). It may have a bitter or licorice-like aftertaste when used in high concentrations (Goyal et al., 2010). However, the reduction of sugar could have several problems as the sugar has unique technological functions, such as texture (mouth feel), bulking and viscosity contribution, preservation by lowering the water activity, and consumers' expectation of sweet taste and flavor specifically like sugar. The reformulated foods with lower sugar content frequently 
show changes in product characteristics against the fullsugar formulation. It remains a challenging task that ought to attend to enhance the quality of low-calorie food products.

Celiac disease or gluten-free sensitive enteropathy is an immune reaction to attack gluten, resulting in inflammation and injury to the small intestine that reduces the ability to absorb nutrients (Shevakani and Singh, 2014). About one in 100-200 people worldwide suffer from the celiac disease by several adverse side effects, including digestive disorders (diarrhea, abdominal pain, bloating and constipation), nutritional deficiency (anemia), fatigue, and weight loss (Demirkesen et al., 2013). Gluten-free diets or food products with no gluten ingredients, such as wheat, rye, and barley, are recommended for celiac patients to reduce the symptoms of the disease (Guimarães et al., 2019).

The objective of this study was to evaluate the quality of gluten-free bars prepared with different ratios of sapodilla-wild almond seed and levels of sugar substitution with stevia. The physical and sensory properties of samples were determined. The preference mapping was constructed to investigate the relevance of product attributes and samples analyzed, and to optimize the most preferred sample.

\section{Materials and methods}

\subsection{Materials}

Sapodilla fruit and wild almond seed were purchased from a local supermarket. Ripe sapodilla fruit was cleaned, peeled, deseeded, and washed again with water. The fruit was homogenized using a blender, and the pulp was kept at $4 \pm 2^{\circ} \mathrm{C}$. The wild almond seed was roasted in an oven $\left(120 \pm 5^{\circ} \mathrm{C}\right)$ for $30 \mathrm{mins}$, and roughly ground. Other ingredients such as sugar, stevia extract powder (BetterSteviaTM, NOW Foods, IL, USA), skim milk, pectin, citric acid, and salt were used.

\subsection{Preparation of sapodilla-wild almond seed bars}

The sapodilla-wild almond seed bar was prepared according to the formulation, as shown in Table 1 . Sapodilla pulp was mixed with roasted wild almond seed, and heated at $60 \pm 2^{\circ} \mathrm{C}$ for 5 mins. Other ingredients such as sugar, stevia, skim milk, pectin, citric acid, and salt were added and continuously stirred for 5 mins. The hot mixture was poured into butter-smeared trays $(15 \times$ $30 \times 2 \mathrm{~cm}^{3}$ ) to $1 / 2 \mathrm{high}$, heated at $60 \pm 2^{\circ} \mathrm{C}$ for $8 \mathrm{hrs}$, cooled, and cut into $1.5 \times 3 \mathrm{~cm}^{2}$ rectangles before storing in a dry place. In this study, fruit bars were made in six formulations based on the ratios of sapodilla pulp and wild almond seed (80/20 and $70 / 30 \mathrm{w} / \mathrm{w})$ and sugar substitution with stevia $(0,1 / 3$ and $2 / 3$ as equivalent sweetness basis; $45 \mathrm{mg}$ stevia powder is equivalent to $6 \mathrm{~g}$ of sugar).

\subsection{Moisture and water activity determination}

The moisture content was determined based on evaporation at $105^{\circ} \mathrm{C}$, according to the method described by the AOAC (1990). The homogenized sample was placed fully at the bottom of a disposable sample cup and measured for water activity using a water activity meter (AquaLab LITE, Decagon devices, Inc., WA, USA). All measurements were done in triplicate.

\subsection{Sensory evaluation}

The sensory test was performed in individual booths under white light. Sixty untrained panelists (age between 18-50 years) who commonly consume fruit bars were recruited from the students and staffs in the Department of Food Science and Technology at the University of the Thai Chamber of Commerce in Thailand. Each panelist was served with 6 samples coded with random threedigit numbers and was instructed to rinse the palate before testing each sample. A 9-point hedonic scale $(1=$ extremely dislike, $9=$ extremely like) was used to evaluate sensorial attributes as follows: color, flavor,

Table 1. Formulation of sapodilla-wild almond seed bars.

\begin{tabular}{lcccccc}
\hline & \multicolumn{5}{c}{ Sapodilla-wild almond seed bar formulation ${ }^{1)}$} \\
\hline Composition $(\mathrm{g})$ & $\mathrm{T} 1$ & $\mathrm{~T} 2$ & $\mathrm{~T} 3$ & $\mathrm{~T} 4$ & $\mathrm{~T} 5$ & $\mathrm{~T} 6$ \\
Sapodilla pulp & 80 & 80 & 80 & 70 & 70 & 70 \\
Wild almond seed & 20 & 20 & 20 & 30 & 30 & 30 \\
Brown sugar & 30 & 20 & 10 & 30 & 20 & 10 \\
Stevia & - & 0.075 & 0.15 & - & 0.075 & 0.15 \\
Pectin & 2.5 & 2.5 & 2.5 & 2.5 & 2.5 & 2.5 \\
Skim milk & 8 & 8 & 8 & 8 & 8 & 8 \\
Citric acid & 0.5 & 0.5 & 0.5 & 0.5 & 0.5 & 0.5 \\
Salt & 0.1 & 0.1 & 0.1 & 0.1 & 0.1 & 0.1 \\
\hline
\end{tabular}

1) Fruit bars prepared with 80/20 of sapodilla pulp and wild almond seed ratio: T1 (full-sugar), T2 (1/3 sugar substitution), and T3 (2/3 sugar substitution), as well as fruit bars prepared with 70/30 of sapodilla pulp and wild almond seed ratio: T4 (fullsugar), T5 (1/3 sugar substitution), and T6 (2/3 sugar substitution). 
texture, and overall acceptability. Panelists were also asked to evaluate their purchasing intention on the fruit bars using a 5 -point scale test $(1=$ certainly would not buy $-5=$ certainly would buy).

\subsection{Statistical analysis}

Mean values of physical and sensory data were compared by the analysis of variance (ANOVA), followed by Duncan's new multiple range test (Cochran and Cox, 1992). The statistical analysis was conducted on the SPSS software for Windows version 17.0. Data observed for physical and sensory analysis were also constructed to the external preference mapping through the principle component analysis (PCA) using the Rprogram (R Core Team, 2013).

\section{Results and discussion}

\subsection{Moisture and water activity measurement}

Results for moisture and water activity determination in Table 2 show significant differences among the fruit bars. The samples with higher sapodilla pulp $(80 \%$ in a mixture) at any sugar substitution had greater moisture and water activity values than those with less sapodilla pulp (70\% in a mixture). It is attributed to different water contents in unbaked fruit bar mixtures, hygroscopicity of sugar, and water evaporation rate (Knecht, 1990). Table 2 also depicted that at constant drying process, T3 and T6 had lowered moisture and water activity than other samples. It is possible due to the $2 / 3$ sugar substitution with stevia can reduce the amount of sugar in the formulation, thereby decreasing the interaction of sugar and water that resulted in the less viscous fruit bar mixture. The lowered viscosity corresponds to the high free water content; thus, the water removal was fast occurred in T3 and T6, reflecting in the dried fruit bars. Chen et al. (2015) reported that the drying rate increased in the dehydration of kiwi slices with high free moisture content. Besides, the water activity observed for T3 $(0.58)$ and T6 (0.53) were below 0.6 (Table 2), indicating that they will have extended shelf-life, even without refrigeration, or save for the growth of pathogens including osmotolerant yeasts (Chen, 2019).

\subsection{Sensory acceptance}

The ANOVA results in Table 2 show that the variation of the sapodilla-wild almond seed ratio and level of sugar substitution have significant influences on all attributes of fruit bars $(p<0.05)$. Regarding the samples prepared with the sapodilla-wild almond seed at 80:20 (T1 to T3), T2 with 1/3 sugar substitution showed similar sensorial attributes to $\mathrm{T} 1$ (full-sugar in the recipe), except for the less flavor score $(\mathrm{p}<0.05)$. Both $\mathrm{T} 1$ and $\mathrm{T} 2$ had darker color and sticky texture, which scored in the "like slightly" level. When increasing to $2 / 3$ sugar substitution with stevia, it was accountable for providing T3 lighter color and chewable texture. The sensory evaluation revealed that $\mathrm{T} 3$ significantly received higher scores of color and texture than $\mathrm{T} 1$ and T2, corresponding to the "like moderately" level. The finding was also corroborated with the moisture analysis in Table 2, as the increase in sugar substitution caused a decrease in moisture content. When the drying temperature $\left(60^{\circ} \mathrm{C}\right)$ and time $(8 \mathrm{hrs})$ were constant for the fruit bar production, the sapodilla-wild almond seed mixture with less sugar content produced lighter color after heating. It is because of the less intensity of brown color from the brown sugar reduction, in association with the less amount of glucose and fructose (non-reducing sugars) interacting with amino acids in the Maillard reaction. This results in lowered Maillard reaction products, which are important for color, flavor, and aroma of the food products (Alais and Linden, 1991; González-Mateo et al., 2009). It was in agreement with Salleh et al. (2017), who reported that the sapodilla fruit bar was darker than the fresh sapodilla pulp. It was attributed to the Maillard browning reaction and the oxidation of yellow-orange or reddish carotenoids during drying. A study conducted by Karp et al. (2016) reported that the lightness of muffin crumb and crust was increased with increasing levels of sucrose substitution with steviol glycosides. Besides, it is noted that the proportion of sapodilla pulp and sugar used in the T3 formulation under this drying process is suitable for making the fruit bar with preferred texture, reflecting in a higher texture score as compared to that of $\mathrm{T} 1$ and $\mathrm{T} 2$ (Table 2).

When considering $\mathrm{T} 4$ to $\mathrm{T} 6$, the decrease in sapodilla pulp proportion from 80 to $70 \%$ influenced the degree of the Maillard browning and product characteristics. The less sapodilla pulp decreased the quantity of nonreducing sugars collaborating within the Maillard reaction, leading to a brighter color. Additionally, it also reduces the amount of water in the formulation, allowing the faster water evaporation during heating. As a consequence, $\mathrm{T} 4$ that contained full-sugar presented a similar chewable texture to $\mathrm{T} 3$ and scored in the "like moderately", whereas T6 with $2 / 3$ sugar substitution showed a drier texture with the "like slightly" level (Table 2). This indicated that most panelists preferred the chewable fruit bar to the hard (dried) one.

The sugar substitution with stevia was feasible, but the higher substitution resulted in decreasing the flavor of the fruit bars. Thus, both samples with $2 / 3$ sugar substitution (T3 and T6) significantly showed the least flavor scores compared to that with $1 / 3$ sugar substitution and full-sugar (Table 2). This observation was 
Table 2. Physical and sensory profile analysis of sapodilla-wild almond seed bars.

\begin{tabular}{lcccccc}
\hline Characteristics & $\mathrm{T} 1$ & $\mathrm{~T} 2$ & $\mathrm{~T} 3$ & $\mathrm{~T} 4$ & $\mathrm{~T} 5$ & $\mathrm{~T} 6$ \\
\hline Physical analysis & \multicolumn{7}{c}{} \\
\hline Moisture content (\%) & $12.85 \pm 0.65^{\mathrm{a}}$ & $12.20 \pm 0.13^{\mathrm{a}}$ & $8.82 \pm 0.27^{\mathrm{c}}$ & $10.70 \pm 0.60^{\mathrm{b}}$ & $10.04 \pm 0.54^{\mathrm{b}}$ & $6.98 \pm 0.42^{\mathrm{d}}$ \\
Water activity & $0.63 \pm 0.02^{\mathrm{a}}$ & $0.63 \pm 0.00^{\mathrm{a}}$ & $0.58 \pm 0.04^{\mathrm{b}}$ & $0.62 \pm 0.00^{\mathrm{a}}$ & $0.61 \pm 0.04^{\mathrm{a}}$ & $0.53 \pm 0.01^{\mathrm{b}}$ \\
\hline Sensory analysis ${ }^{1)}$ & \multicolumn{7}{c}{} & & & \\
\hline Color & $6.85 \pm 1.15^{\mathrm{b}}$ & $6.95 \pm 1.11^{\mathrm{b}}$ & $7.82 \pm 0.93^{\mathrm{a}}$ & $7.85 \pm 0.65^{\mathrm{a}}$ & $7.00 \pm 1.10^{\mathrm{b}}$ & $6.64 \pm 1.20^{\mathrm{b}}$ \\
Flavor & $7.34 \pm 1.00^{\mathrm{a}}$ & $7.02 \pm 1.02^{\mathrm{b}}$ & $6.00 \pm 0.95^{\mathrm{c}}$ & $7.31 \pm 0.92^{\mathrm{a}}$ & $6.86 \pm 0.79^{\mathrm{b}}$ & $6.00 \pm 0.70^{\mathrm{c}}$ \\
Texture & $6.24 \pm 0.72^{\mathrm{b}}$ & $6.28 \pm 0.96^{\mathrm{b}}$ & $7.46 \pm 1.02^{\mathrm{a}}$ & $7.40 \pm 1.08^{\mathrm{a}}$ & $6.25 \pm 0.67^{\mathrm{b}}$ & $6.35 \pm 0.85^{\mathrm{b}}$ \\
Overall acceptability & $6.72 \pm 0.90^{\mathrm{b}}$ & $6.88 \pm 1.05^{\mathrm{b}}$ & $7.28 \pm 1.06^{\mathrm{a}}$ & $7.44 \pm 0.88^{\mathrm{a}}$ & $6.51 \pm 0.58^{\mathrm{c}}$ & $6.04 \pm 1.01^{\mathrm{d}}$ \\
\hline Purchasing intention $(\% \text { frequency distribution })^{2)}$ & & & & \\
\hline Score 1 & 7 & 5 & 4 & 5 & 8 & 5 \\
Score 2 & 17 & 18 & 7 & 7 & 22 & 22 \\
Score 3 & 8 & 12 & 11 & 9 & 10 & 25 \\
Score 4 & 32 & 23 & 30 & 31 & 17 & 14 \\
Score 5 & 36 & 42 & 48 & 48 & 43 & 34 \\
\hline
\end{tabular}

Means in the same row with different superscripts are significantly different $(\mathrm{p}<0.05)$.

${ }^{1)}$ Based on a 9-point hedonic scale $(1=$ extremely dislike, 9 = extremely like).

${ }^{2)}$ Based on a 5 -point structured scale $(1=$ certainly would not buy, $5=$ certainly would buy).

T1 to T6 refer to Table 1.

presumably because of less amount of sugar in the Maillard reaction, reduction of brown sugar flavor, no browning formation of the stevia, and different sweet styles between sugar and stevia (Martínez-Cervera et al., 2014; Gao et al., 2016). Some panelists note their comments "slightly bitter aftertaste" on the samples with $2 / 3$ sugar substitution or high stevia content, implying that the fruit bar will be more accepted if the aftertaste is decreased or masked.

For overall acceptability evaluation, the data were classified into three groups: (1) "dislike" group (score 13), (2) "indifferent" group (score 4-6), and (3) "like" group (score 7-9). The higher sapodilla pulp samples (T1 to T3) showed a higher average frequency distribution rating for the "like" group (67\%) compared to those with the lower one (T4 to T6) (58\%) (Figure 1). When considering the most acceptance, the highest percentage for the "like" group was observed for T4 (92\%), followed by the T3 $(85 \%)$, as confirmed by the highest overall acceptability in Table 2 . It indicated that most panelists preferred the color and texture of both $\mathrm{T} 4$ and T3, which influenced the overall acceptability. Compared with the dried fruit bars (T5 and T6), the sticky fruit bars (T1 and T2) generally showed a higher percentage in the "like" group and a lower percentage in the "indifferent" group (Figure 1). It implies that the way the sticky texture of fruit bars breaks down in the mouth (mastication) relates to higher overall acceptability against that with dried texture. The $\mathrm{T} 6$ result, in particular, shows some panelists $(3 \%)$ are ready to change their feeling from the "indifferent" to "dislike", indicating that the texture is the vital attribute influencing the consumer preference. This is additional information obtained from this technique.

When considering the purchase intention (Table 2), the consumers who would both certainly buy (score 5) and possibly buy (score 4) $\mathrm{T} 3$ and $\mathrm{T} 4$ were $78 \%$ and $79 \%$, respectively. The result showed that both fruit bars were well-accepted.

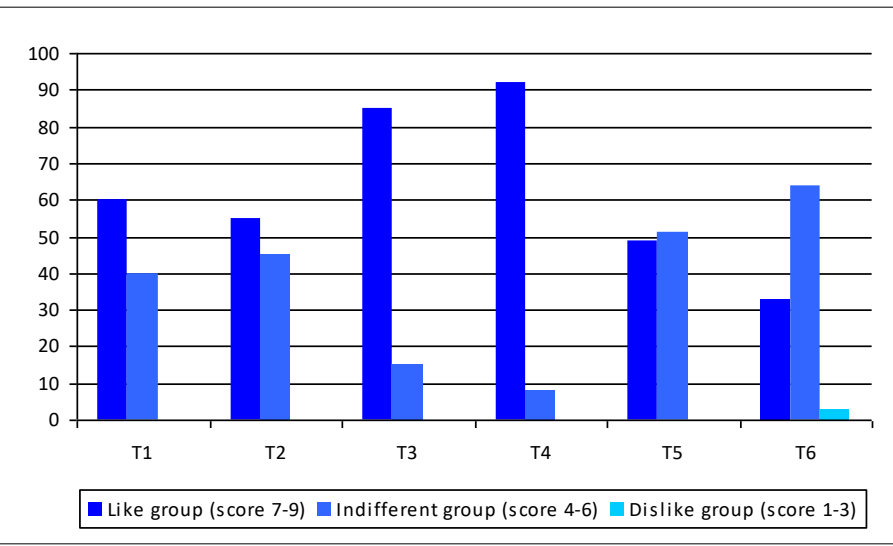

Figure 1. Frequency distribution (\%) of three groups classified from overall acceptability scores of sapodilla-wild almond seed bars. T1 to T6 refer to Table 1 .

\subsection{Principle component analysis}

The PCA was performed to evaluate the fruit bars based on the relevance of physical parameters and panelists' perception. The first principle component (D1) explained $54.86 \%$ of the total variability, and the second principle component (D2) explained $42.35 \%$ of the total variability (Figure 2). The high accumulative value 
(97.21\% in total) indicated that the panelists could discriminate satisfactorily between the samples and product attributes. In the D1 axis, overall acceptability, flavor, moisture, and water activity showed positive correlations (Figure 2a). All of these contributed to distinguish the T4 from other samples. As seen in Figure $2 \mathrm{~b}$, the T4 was positioned on the right in the same quadrant of overall acceptability, revealing that it was superior in sensory quality. The $\mathrm{T} 1$ and $\mathrm{T} 2$, which located next to T4, were characterized by less sensorial acceptance, higher moisture, and water activity. The T6, which was positioned on the far left, presented the lowest moisture, water activity, and overall acceptability.

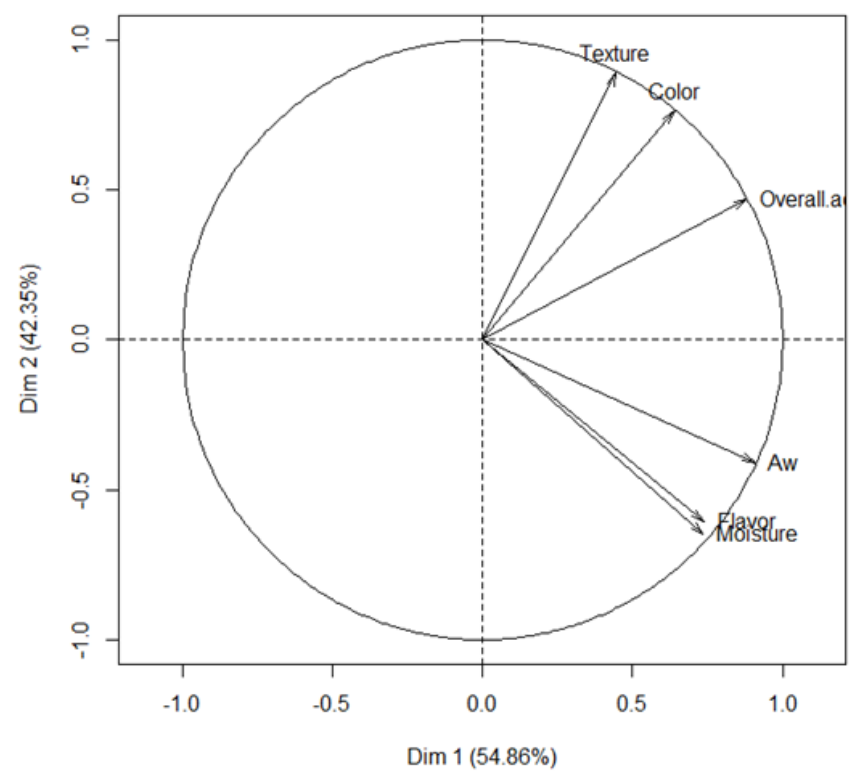

(a) Projection of variables

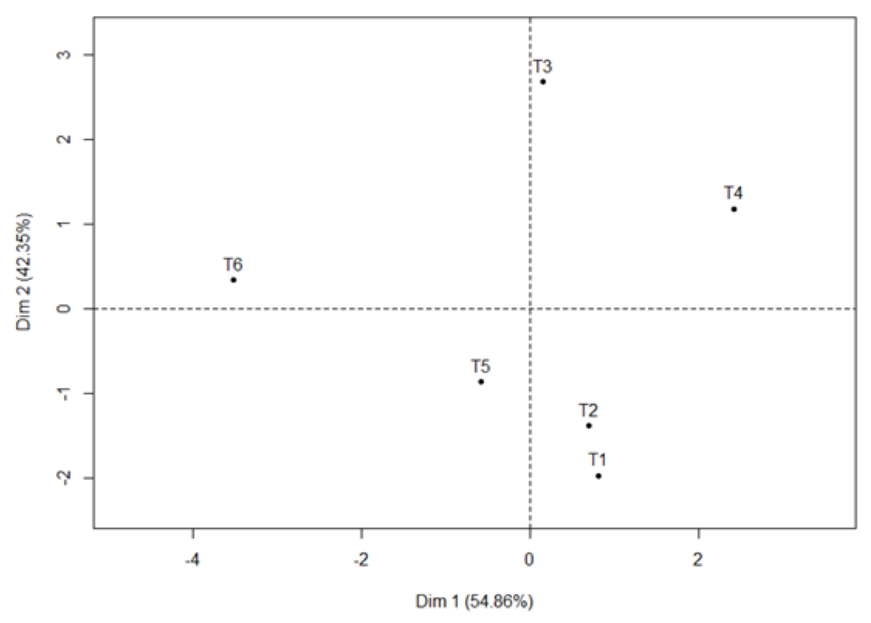

(b) Projection of sapodilla-wild almond seed bars

Figure 2. Preference mapping for sensory attributes and physical parameters of the fruit bars: (a) projection of variables and (b) projection of sapodilla-wild almond seed bars. T1 to T6 refer to Table 1.

In the D2 axis, both $\mathrm{T} 3$ and $\mathrm{T} 4$ were stood out in the same quadrant, which was positively correlated with the texture and color (Figure 2a-b). Comparatively, T3 was located nearby the attributes of texture and color; thus, it was characterized by having more desirable texture and color. It was confirmed by the higher liking scores for texture and color as compared to other formulations (Table 2). While $\mathrm{T} 1$ and $\mathrm{T} 2$ were negatively correlated with these attributes, consequently showing less desirable texture and color. The more sapodilla pulp and sugar content resulted in a higher intensity of brown color through the Maillard reaction. Therefore, $\mathrm{T} 1$ and $\mathrm{T} 2$ were darker than $\mathrm{T} 3$ and $\mathrm{T} 4$, which were less preferred by the panelists. For the texture acceptance, the amount of sapodilla pulp and sugar used in T3 and T4 was extraordinarily balanced and made the desirable (chewable) texture fruit bars against the sticky ones.

For the sapodilla-wild almond seed (80:20) fruit bars (T1 to T3), a close distance between $\mathrm{T} 1$ and $\mathrm{T} 2$ (Figure $2 \mathrm{~b}$ ) indicated that the $1 / 3$ sugar substitution in T2 slightly affected the sensory quality (flavor and overall acceptability), water activity and moisture compared to the full-sugar (T1). However, T3, which was located opposite to $\mathrm{T} 1$ and $\mathrm{T} 2$, indicated that the $2 / 3$ sugar substitution made the sample more textural perception. For the sapodilla-wild almond seed (70:30) fruit bars, it was found that $\mathrm{T} 4$ was located on the right (most acceptability), followed by $\mathrm{T} 5$ at the center (moderate acceptability) and $\mathrm{T} 6$ on the left (least acceptability) (Figure 2b). This result suggests that, when used less sapodilla pulp proportion, a substantial decrease in consumer preference will occur in fruit bar formulations with higher sugar substitution.

It is to say that preference mapping is a useful tool that reveals a powerful correlation between physical and sensory variables, individual preference, and consumer trend. It can evaluate the importance of product attributes, which have the highest impact on sensorial acceptance and orientation of consumer preference for fruit bars. Thus, it provides a perfect account of consumer preference against the ANOVA technique, which shows the same/difference between average scores of attributes, but no direction on which sample is higher or lower acceptability. According to preference mapping results, consumer acceptance is oriented towards the T4 and T3. This indicates that, as with the high sensory quality, the full-sugar in the formulation $(30 \mathrm{~g})$ is required if the sample is prepared with less sapodilla pulp (70\%) (T4). On the other hand, the $2 / 3$ sugar substitution with stevia is needed for the sample with higher sapodilla pulp (80\%) (T3). In line with the healthy target, T3 is a recommended formulation since the sample has preferable texture, less sugar content, and extended storage owning to low water activity $(<0.6)$. 


\section{Conclusion}

Two local agriculture, sapodilla pulp and wild almond seed can be successfully used in the manufacture of gluten-free, less sugar fruit bars made with stevia. The fruit bar formulated with the sapodilla-wild almond seed at 80:20 had higher moisture, water activity, dark color, and sticky texture than those with the 70:30 mixture. The $1 / 3$ sugar substitution with stevia did not affect the quality of the sapodilla-wild almond seed (80:20) bar, while a better texture was found with $2 / 3$ sugar substitution. On the other hand, the sapodilla-wild almond seed (70:30) bar with 2/3 sugar substitution was drier and received the least preferred. Great consideration of sapodilla pulp and sugar content encourages the quality and perception of the fruit bars. The preference mapping effectively identifies the preferred attributes of fruit bars and optimizes product acceptance. The healthy fruit bar formulation could be prepared using the sapodilla-wild almond seed at 80:20 with $2 / 3$ sugar substitution with stevia.

\section{Conflict of Interest}

The authors declare no conflict of interest.

\section{Acknowledgments}

The authors thank the University of the Thai Chamber of Commerce in Thailand for supporting this study.

\section{References}

Alais, C. and Linden, G. (1991). Food Biochemistry. London: Ellis Horwood. https://doi.org/10.1007/978$1-4615-2119-8$

AOAC. (1990). Official Method of Analysis. $15^{\text {th }}$ ed. Arlington, VA: Association of Official Analytical Chemists.

Chen, C. (2019). Relationship between water activity and moisture content in floral honey. Foods, 8(1), 30-48. https://doi.org/10.3390/foods 8010030

Chen, S.K., Siew, E.S. and Soon, W.L. (2015). Drying characteristics and quality evaluation of kiwi slices under hot air natural convective drying method. International Food Research Journal, 22, 2188-2195.

Cochran, W.G. and Cox, G.M. (1992). Experimental Designs. $2^{\text {nd }}$ ed. New York: Wiley.

Demirkesen, I., Sumnu, G. and Sahin, S. (2013). Quality of gluten-free bread formulations baked in different ovens. Food and Bioprocess Technology, 6, 746-753. https://doi.org/10.1007/s11947-011-07126
Gao, J., Brenan, M.A., Mason, S.L. and Brenan, C.S. (2016). Effect of sugar replacement with Stevianna and inulin on the texture and predictive glycaemic response of muffins. International Journal of Food Science and Technology, 51(9), 1979-1987. https:// doi.org/10.1111/ijfs.13143

González-Mateo, S., González-SanJosé, M.L. and Muñiz, P. (2009). Presence of Maillard products in Spanish muffins and evaluation of colour and antioxidant potential. Food and Chemical Toxicology, 47(11), 2798-2805. https:// doi.org/10.1016/j.fct.2009.08.015

Goyal, S.K., Samsher and Goyal, R.K. (2010). Stevia (Stevia rebaudiana) a bio-sweetener: A review. International Journal of Food Science and Nutrition, 61(1), 1-10. https:// doi.org/10.3109/09637480903193049

Guimarães, R.M., Pimentel, T.C., de Rezende, T.A.M., de Santana-Silva, J., Falcão, H.G., Ida, E.I. and Egea, M.B. (2019). Gluten-free bread: Effect of soy and corn co-product on the quality parameters. European Food Research and Technology, 245, 1365-1376. https://doi.org/10.1007/s00217-01903261-9

Karp, S., Wyrwisz, J., Kurek, M. and Wierzbicka, A. (2016). Physical properties of muffins sweetened with steviol glycosides as the sucrose replacement. Food Science and Biotechnology, 25, 1591-1596. https://doi.org/10.1007/s10068-016-0245-x

Knecht, R.L. (1990). Properties of Sugar. In Pennington, N.L. and Baker, C.W. (Eds.). Sugar, p. 46-65. New York: Van Nostrand Reinhold.

Lim, W.S., Rebeta, M.S. and Uthumporn, U. (2018). Utilization of functional beverage from sapodilla (Manilkara zapota L.) fruit. Food Research, 2(2), 163-170. https://doi.org/10.26656/fr.2017.2(2).227

Martínez-Cervera, S., Salvador, A. and Sanz, T. (2014). Comparison of different polyols as total sucrose replacers in muffins: Thermal, rheology, texture and acceptability properties. Food Hydrocolloids, 35, 18. https://doi.org/10.1016/j.foodhyd.2013.07.016

R Core Team. (2013). R: A language and environment for statistical computing. R Foundation for Statistical Computing, Vienna, Austria. Retrieved from R Core Team website: http://www.R-project.org/

Rudrappa, U. (2019). Sapodilla (Manilkara zapota L.) nutrition facts. Retrieved on April 5, 2019. Website: https://www.nutrition-and-you.com/sapodilla.html

Salleh, R.M., Ying, T.L. and Mousavi, L. (2017). Development of fruit bar using sapodilla (Manilkara zapota L.). Journal of Food Processing and Preservation, 41(2), e12806. https://doi.org/10.1111/ 
jfpp.12806

Shevakani, K. and Singh, N. (2014). Influence of kidney bean, field pea and amaranth protein isolates on the characteristics of starch-based gluten-free muffins. International Journal of Food Science and Technology, 49(10), 2237-2244. https:// doi.org/10.1111/ijfs. 12537

Sinchaipanit, P., Kerr, W.L. and Chamchan, R. (2013). Effect of sweeteners and hydrocolloids on quality attributes of reduced-calorie carrot juice. Journal of the Science of Food and Agriculture, 93(13), 3304 3311. https://doi.org/10.1002/jsfa.6176

Sonwai, S. and Pornprachanuvat, P. (2012). Characterization of physicochemical and thermal properties and crystallization behavior of Krabok (Irvingia malayana) and rambutan seed fats. Journal of Oleo Science, 61(12), 671-679. https:// doi.org/10.5650/jos.61.671 